\title{
LONG-TERM EVOLUTION OF SAND AND GRAVEL BEACHES ON THE MIYAZAKI COAST
}

\author{
Shinji Sato ${ }^{1}$, Shun Kishimoto ${ }^{2}$ and Haruna Hiramatsu ${ }^{2}$
}

\begin{abstract}
Long-term evolution of Miyazaki Coast was investigated in terms of four aspects, geology and geography, comparison of shoreline in available maps and photographs, sediment retention analysis in watershed scale and sediment size as well as luminescence measurements of foreshore sediments. Geological and geographical analysis revealed steep topography in northern part and fluvial plain on the southern part. The total rate of sediment retention in reservoirs was found to be as much as 1.9 million $\mathrm{m}^{3} /$ year. Historical shoreline retreat in the recent 200 years was significant in the northern region whereas severe erosion was developed in the last decades on the southern region close to the rivermouths of the Hitotsuse River and the Ooyodo River. The sand grain size and the thermoluminescence intensity were both found to decrease from north to south, implying the dominant direction of longshore sand transport is from north to south.
\end{abstract}

Keywords: long-term morphology; longshore transport; thermoluminescence

\section{INTRODUCTION}

Miyazaki coast is located on the south part of Japan, facing the Pacific Ocean. It is a $70 \mathrm{~km}$ beach, running almost from north to south, covered with gravels in the northern part and fine sand in the southern part as shown in Fig. 1. Beach sediments are supplied from four major rivers, Mimigawa River, Omaru River, Hitotsuse River and Ooyodo River. Severe coastal erosion has been observed in recent years especially on the Sumiyoshi Beach located in the southern region near the rivermouth of the Ooyodo River.

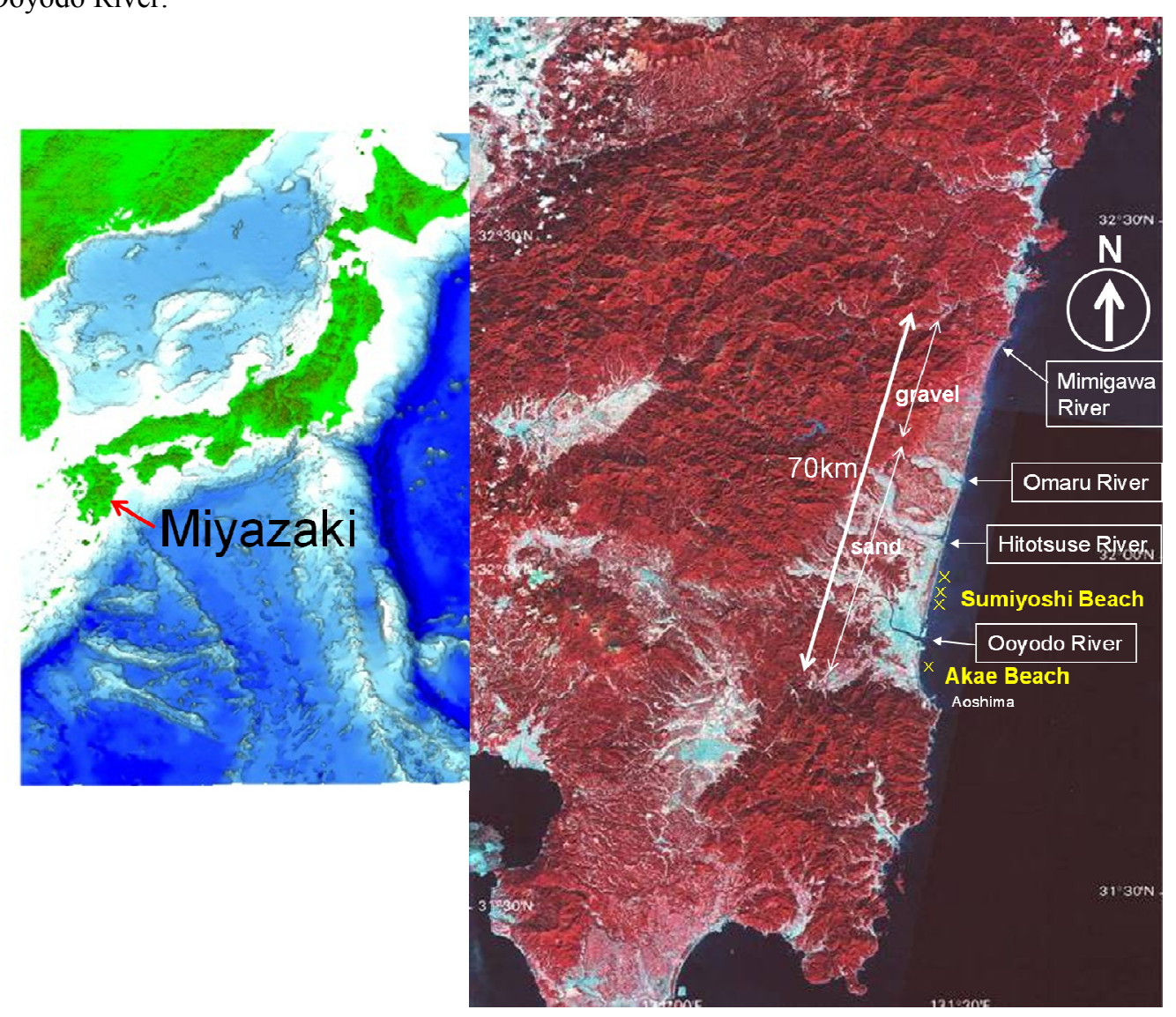

Figure 1 Miyazaki Coast and major four rivers

\footnotetext{
${ }^{1}$ Department of Civil Engineering, The University of Tokyo, 7-3-1, Hongo, Tokyo, 113-8656, JAPAN

${ }^{2}$ Former Graduate Student, Department of Civil Engineering, The University of Tokyo
} 
Figure 2 shows aerial photos taken in 1971 and 2005 around the rivermouth of the Ooyodo River. Coastal morphology around the rivermouth is characterized by a slightly protruding shoreline and lagoons on the both sides of the river. The lagoon areas have been utilized for port and airport. Coastal erosion becomes accelerated since 1990's with the introduction of many structures such as coastal road, port breakwaters and extended airport runways. Photo 1 shows the situation of the eroding Sumiyoshi Beach at the north end of the coastal revetment introduced to protect the coastal road. The picture was taken half year after the attack of a typhoon. Tentative protection structures were introduced in front of the coastal road. Looking at the shape of eroded beach, it is considered that the direction of longshore transport is from south to north, since the north end of structure is severely eroded. However, it is difficult to determine the direction on the long-term basis since the incident wave angle is highly variable on this coast.

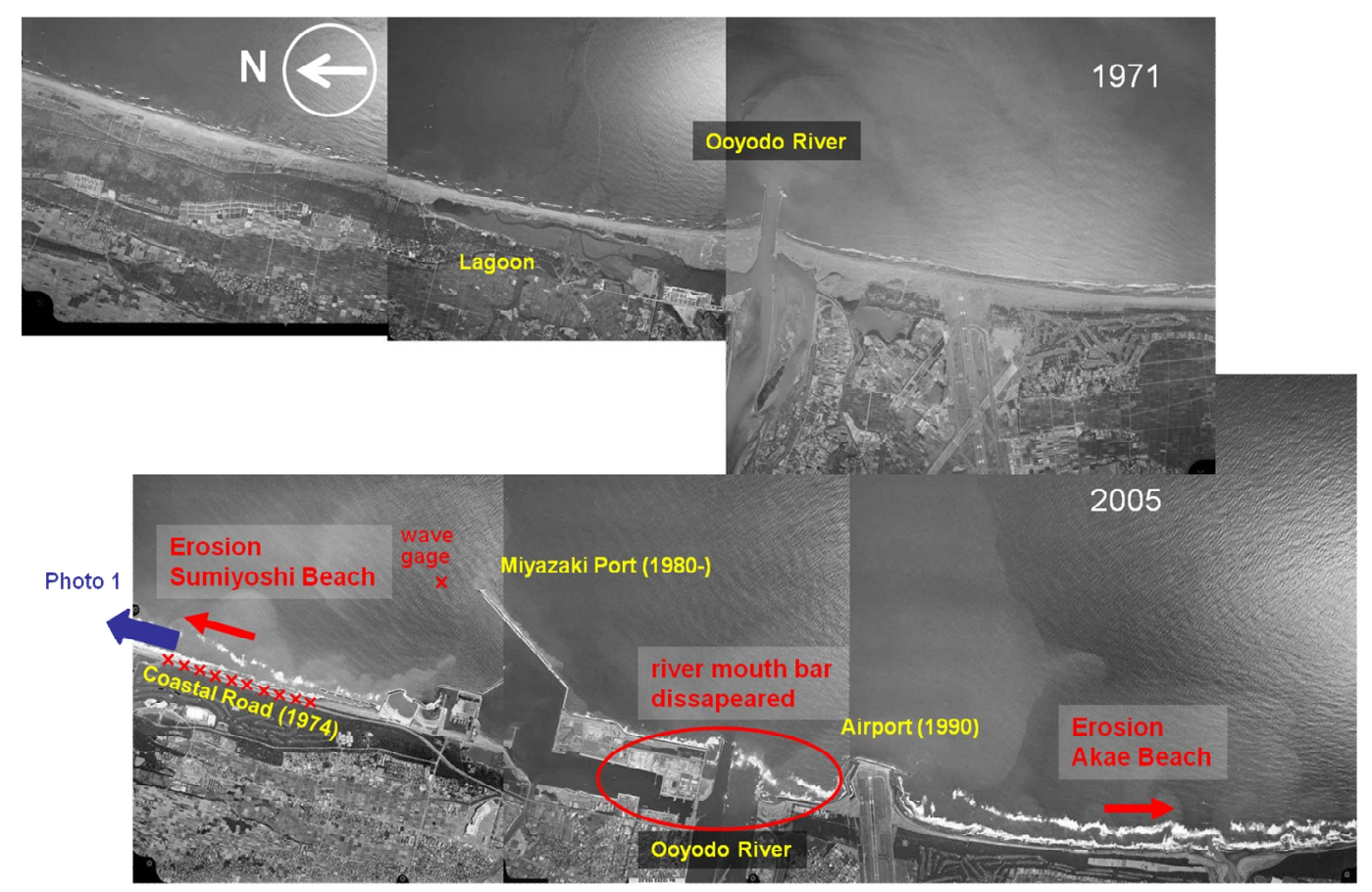

Figure 2 Comparison of aerial photographs in 1971 and 2005

Figure 3 illustrates the distribution of incident wave angle in ten years from 1992 to 2002, in which the horizontal axis denotes the incident wave angle from the north and the vertical axis represents the fraction of wave energy flux. Wave data are obtained at the tip of the breakwater of the Miyazaki Port located on the left side of the Ooyodo rivermouth (see Fig. 2). The angle normal to the shoreline is 105 degrees east from the north. Although the mean wave angle is almost normal to the shore, two peaks are noticed representing typhoon waves (incident from south) and winter storm waves (incident from north) respectively. From the analysis of wave data alone, it is hard to determine the direction of the longshore sand transport on the long-term basis.

In order to understand the long-term morphology of the Miyazaki Coast, analyses were made in this study on the following four aspects; (1) geography and geology, (2) sediment retention in reservoirs, (3) shoreline change revealed from existing maps and aerial photographs, and (4) beach sediment size and luminescence. 


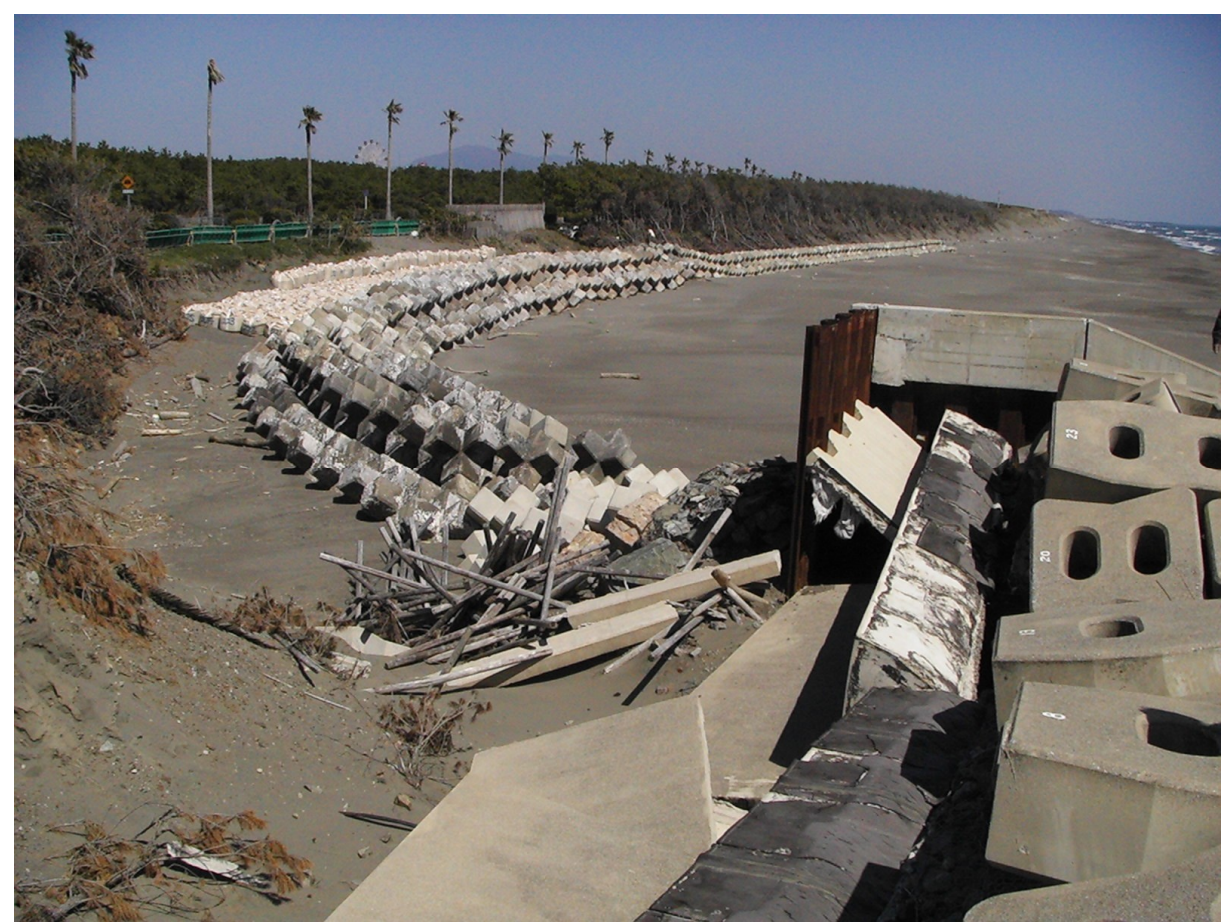

Photo 1 Erosion at the north end of coastal revetment, Sumiyoshi Beach (March 29, 2006)

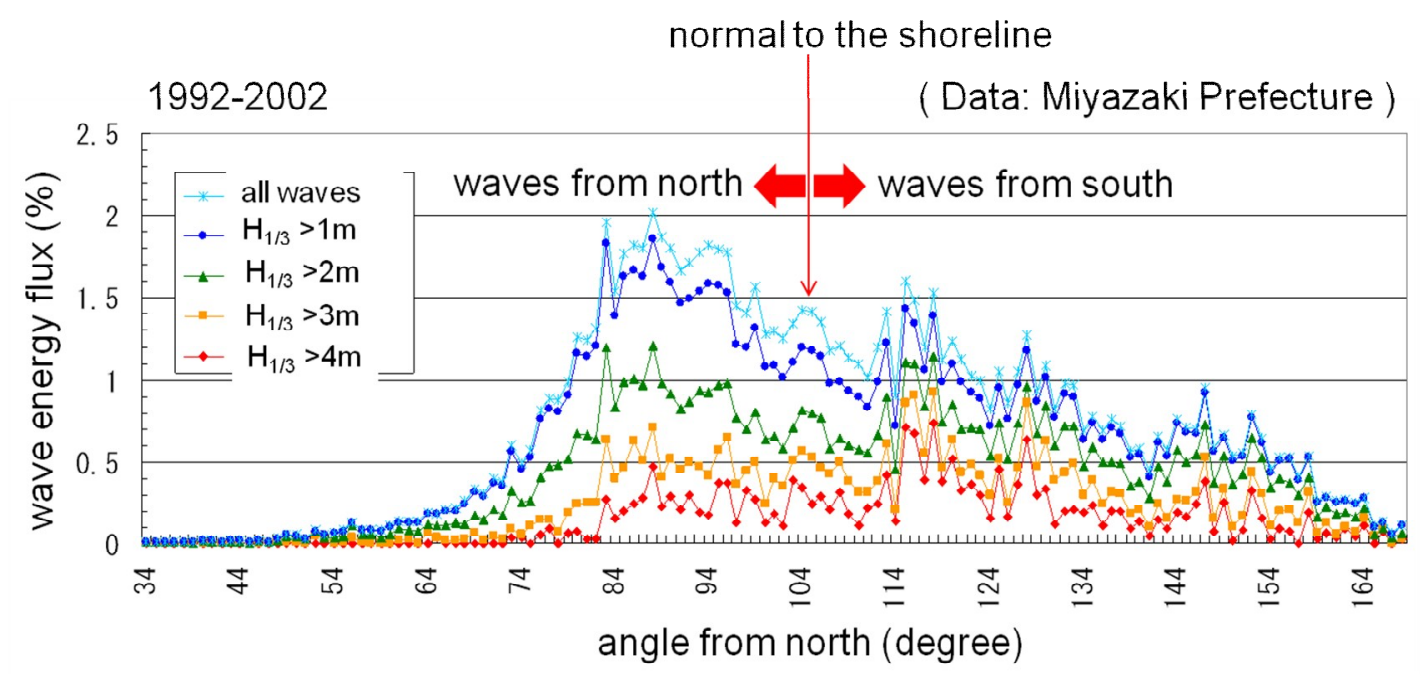

Figure 3 Distribution of incident wave angle at the Miyazaki Port in a period from 1992 to 2002 (Miyazaki Prefecture).

\section{GEOLOGY AND GEOGRAPHY}

The Miyazaki plain is characterized by the presence of the late Tertiary fluvial terraces created by uplifting tectonic movement, bounded by mountains and hills in the northern region and by a fluvial plain in the south end as illustrated in Fig. 4. The coast is covered with gravels in the northern part and fine sand in the southern part. The north end and the south end of the coast are bounded by rocky capes, so that longshore sediment fluxes across both boundaries can be ignored. Beach sediments are supplied from four major rivers, Mimigawa River, Omaru River, Hitotsuse River and Ooyodo River. Offshore bathymetries at the depth of 60 to $70 \mathrm{~m}$ are supposed to represent the shoreline in the last glacier age, 
when the sea level was 60 to $70 \mathrm{~m}$ lower than the present sea level for a relatively long duration of more than 30 thousands years. Although wave climate in the glacier age is different from that of the present age, the dominant wave direction can be estimated from the shape of the corresponding contour lines since the sea level then was stable for a relatively long period. They indicate that the shoreline at that age runs from north to south whereas the present shoreline is concave compared from the equilibrium shape. This suggests that the concave region on the south will be filled by sediments if the sea level is kept unchanged. The longshore sand transport on the present non-equilibrium beach is therefore considered to be from north to south. In order to demonstrate such long-term sedimentary processes, further analysis will be required on the dating of sedimentary processes in the offshore zone by using OSL/TL techniques.

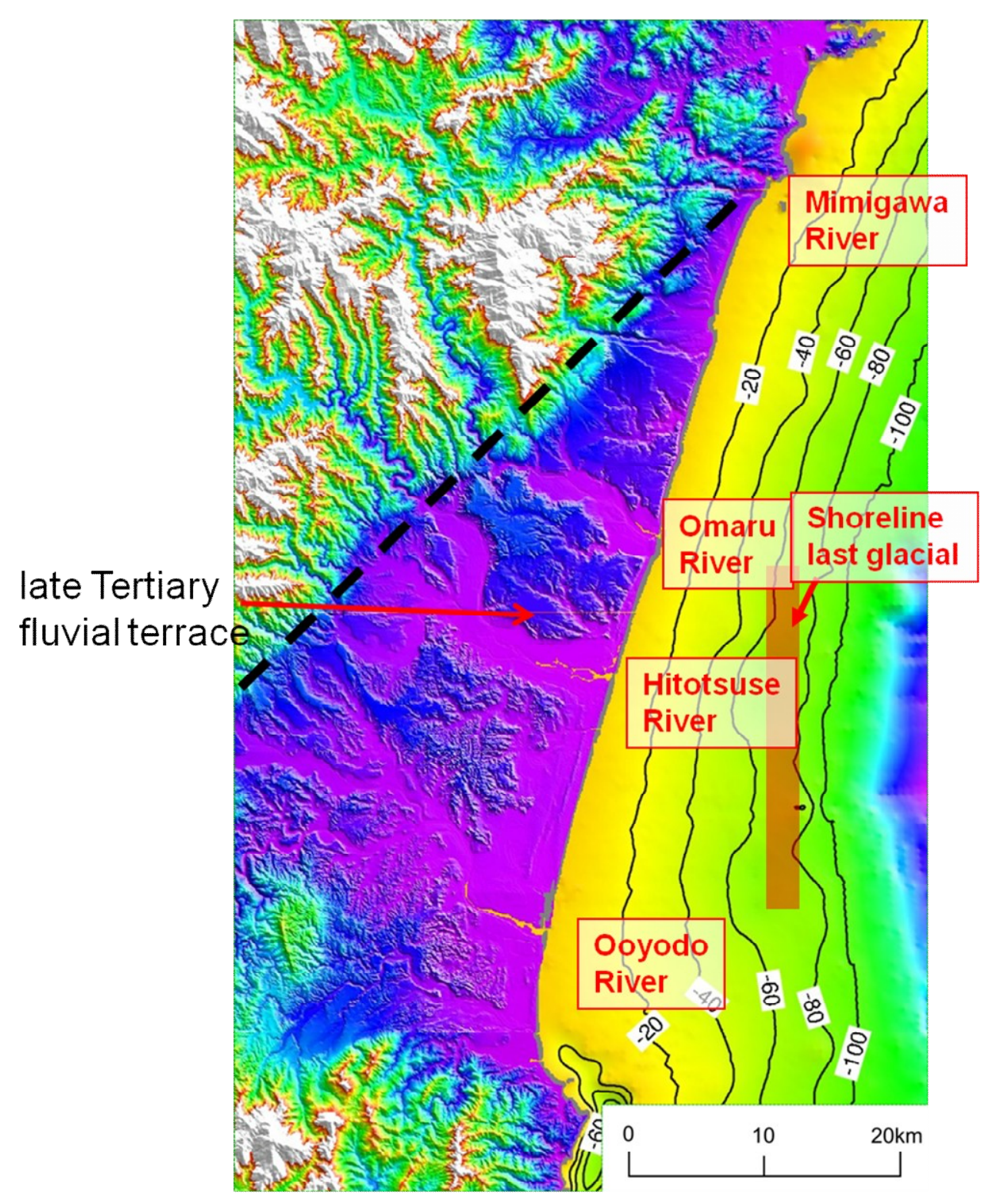

Figure 4 Geology and geography of the Miyazaki Coast 


\section{SEDIMENT RETENTION IN RESERVOIRS}

The watersheds of the four rivers are characterized by huge production of sediments. Many dams were constructed in the tributaries of the four rivers in the $20^{\text {th }}$ century, interrupting the sediment flow. Photo 2 shows a typical land slide developed by a typhoon in 2005 in the watershed of the Mimigawa River. The land slide was developed on the downstream of the Tsukabaru Dam. In most of dams in the watershed, like Tsukabaru Dam in Photo 2, a large amount of sediments has been accumulated in the reservoir. Figure 5 illustrates the sediment retention for two high dams in the Omaru River watershed. Sediments are accumulated steadily for both Matsuo Dam and Dogawa Dam. The rate of sediment retention for the two dams in recent years is calculated at 300 thousand cubic meter per year. Figure 6 shows the specific sediment yields $q_{s}$ calculated by the rate $Q_{s}$ of sediment retention in the reservoir divided by the catchment area $A$. The straight line in the figure indicates a relationship between $q_{s}$ and $A$, which was proposed by Ashida and Okumura (1974). The specific sediment yields for Tenryu River and Kurobe River were also shown in Figure 6, which were located in the highest sediment yield zone in Japan. The specific sediment yields for the four rivers are found to be at a high level categorized as the second largest sediment production group in Japan. Because of steep slope of the river profile as shown in Figure 7, the interruption of sediment flow is significant especially for rivers in the northern region. The total sediment retention rate in 23 reservoirs existing in the watersheds of four rivers was found to be 1.9 million $\mathrm{m}^{3} /$ year, which is of the same order with the sediment retention in the Sakuma Dam reservoir, which is the largest dam in Japan located in the Tenryu River watershed. Owing to the interruption of sediment flow at dams, more than $3 \mathrm{~m}$ degradation of riverbed was observed on the downstream of the Omaru River and sand bar at the river mouth has been disappeared for the Ooyodo River as confirmed in Figure 2. Sediment discharge through the four rivers is thus considered to decrease considerably.

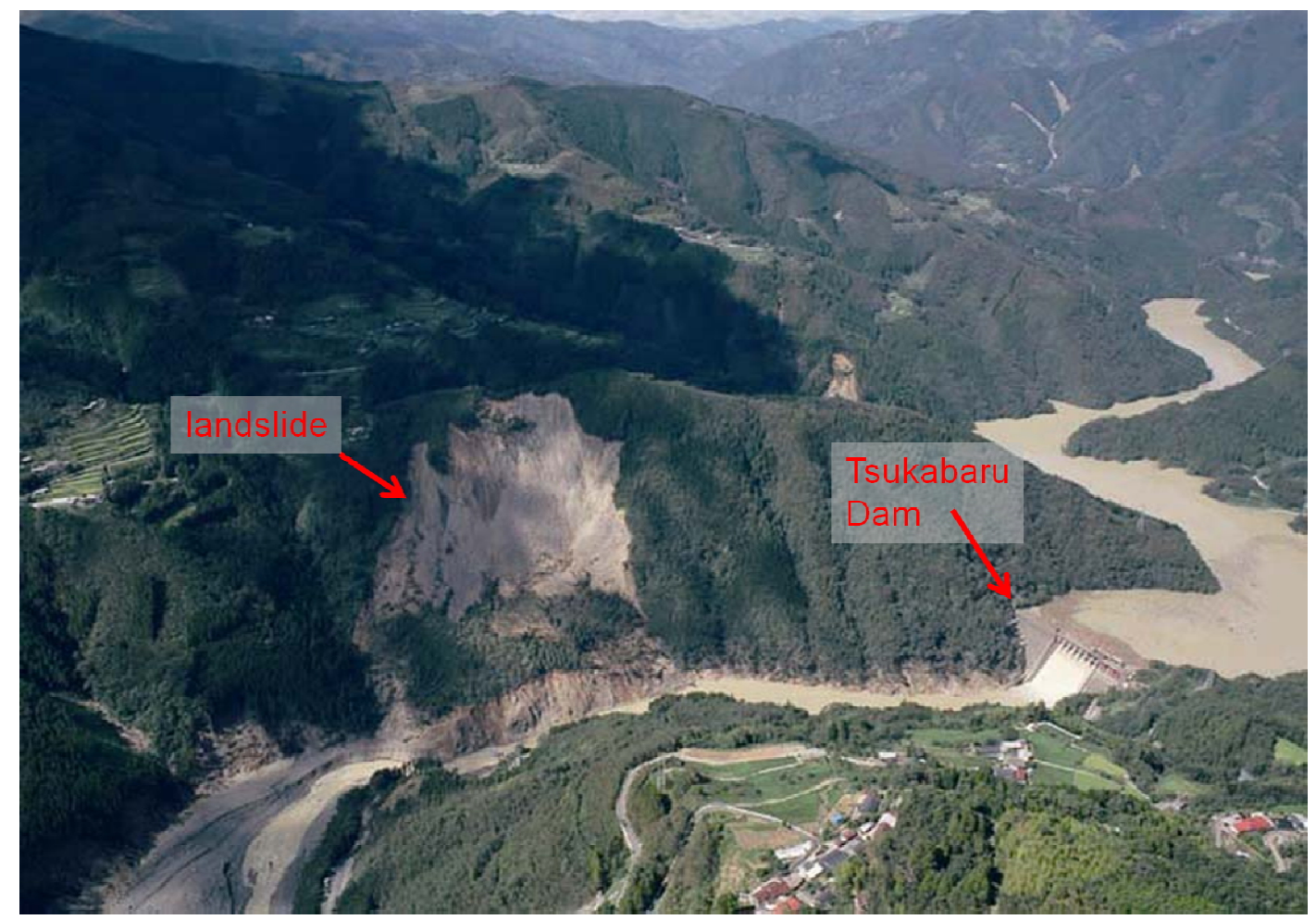

Photo 2 Typical landslide developed near Tsukabaru Dam, Mimigawa River (Miyazaki Prefecture, September 2005). 


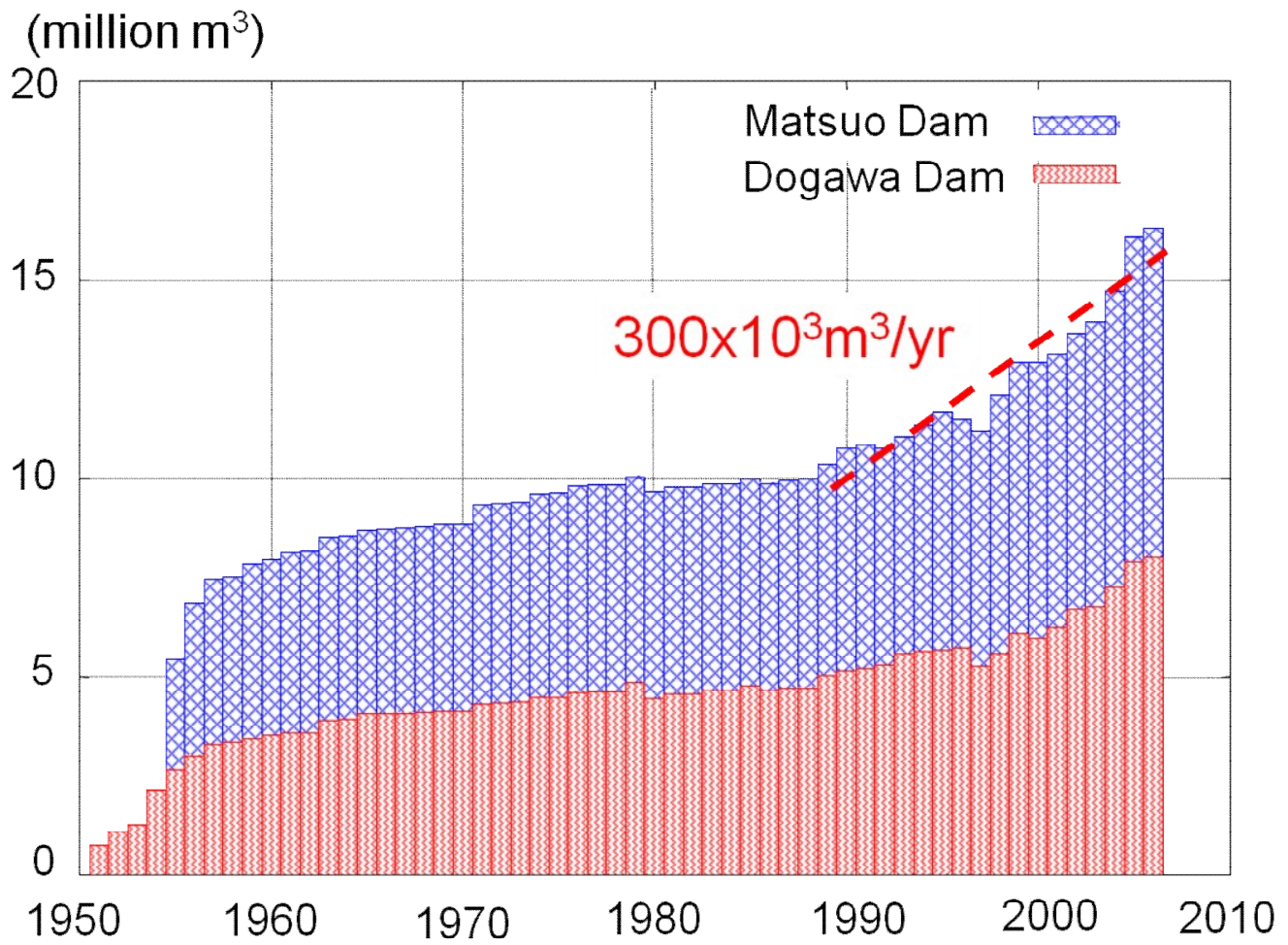

Figure 5 Sediment retention in reservoirs of Matsuo Dam and Dogawa Dam, located in the Omaru River watershed (Miyazaki Prefecture).

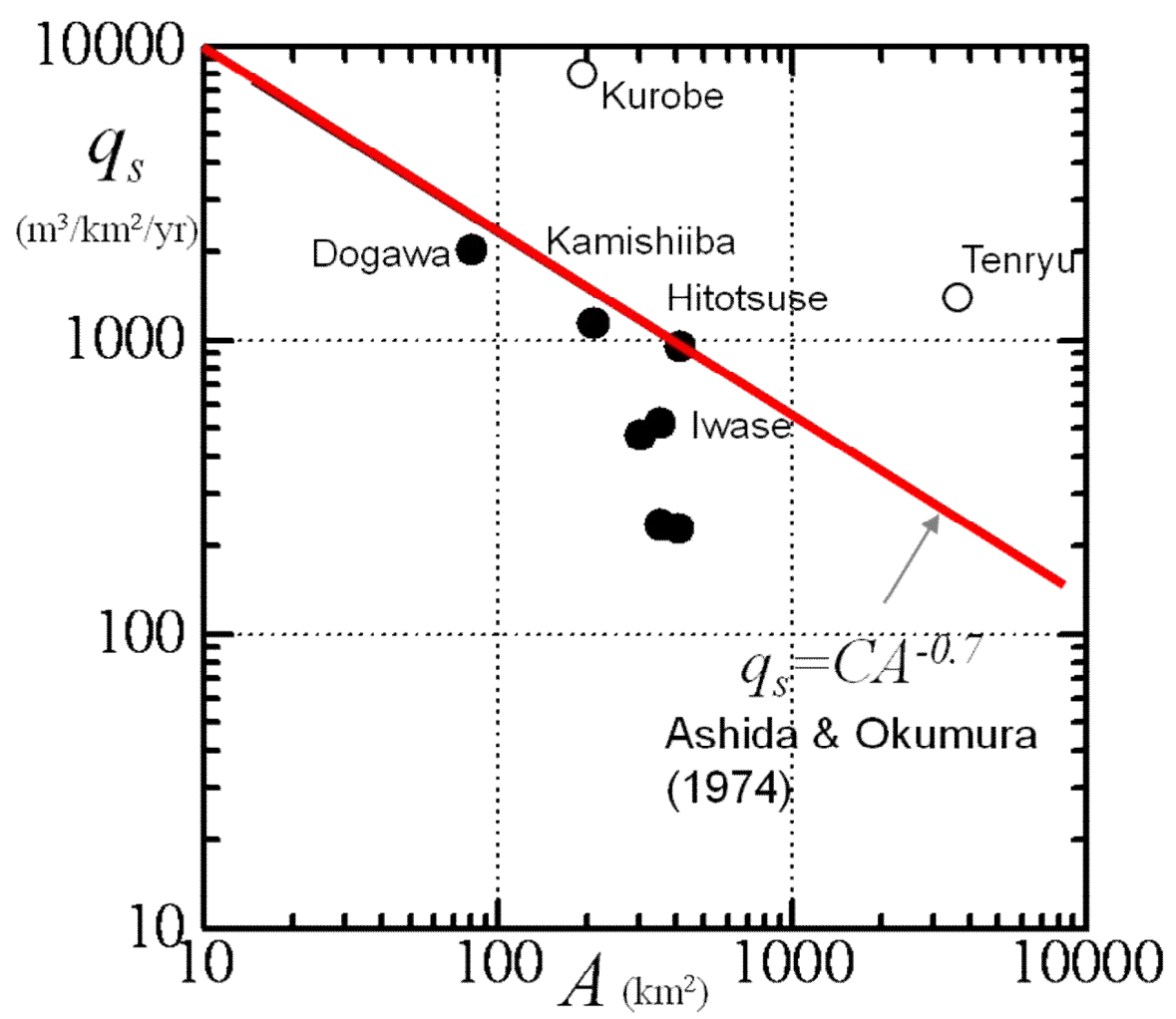

Figure 6 Specific sediment retention rate in reservoirs of watersheds of four rivers (Miyazaki Prefecture). 


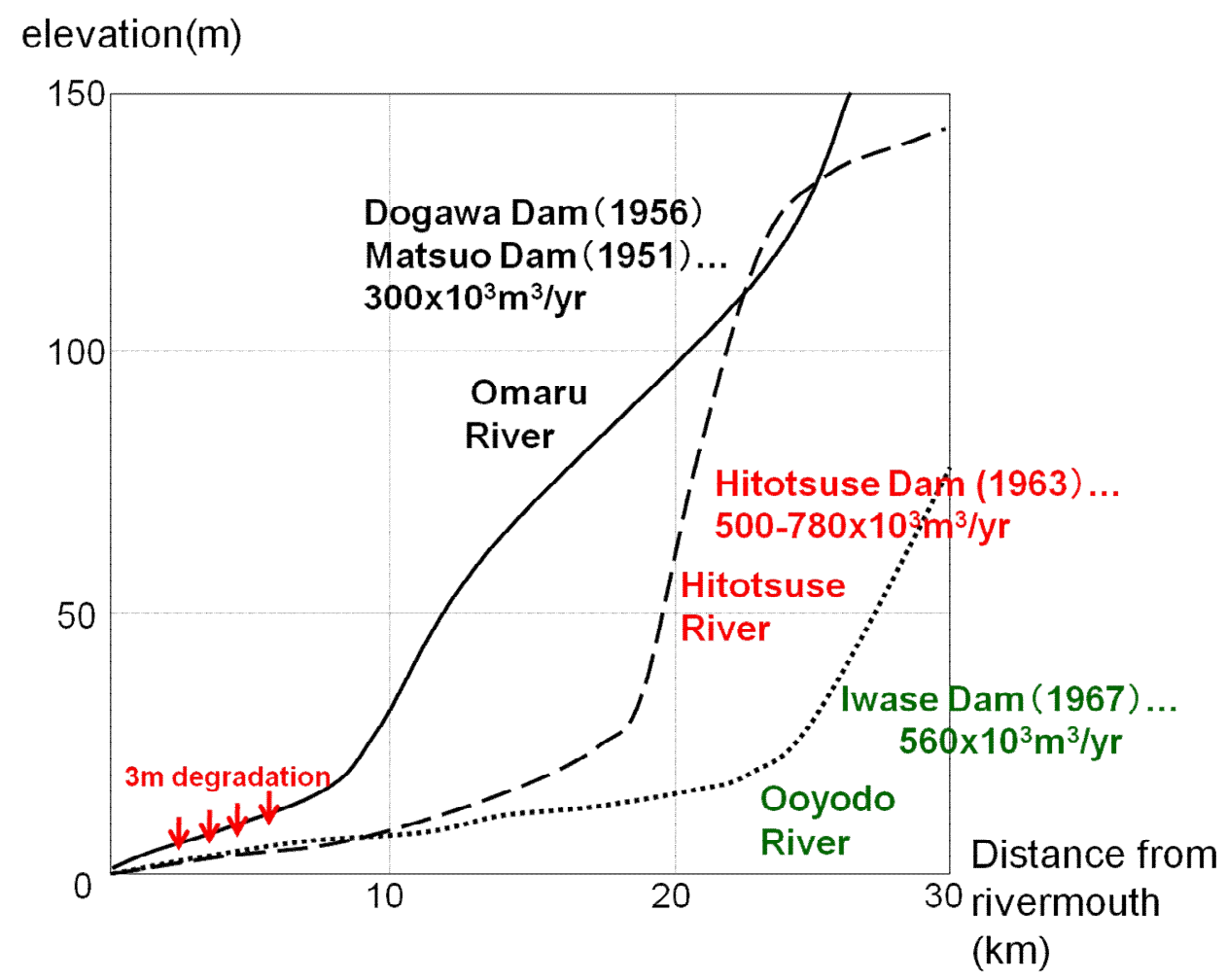

Figure 7 Riverbed profiles and sediment retention in reservoirs for Omaru River, Hitotsuse River and Ooyodo River (Miyazaki Prefecture).

\section{SHORELINE CHANGE IN 200 YEARS}

Shoreline change in the last 200 years was investigated by comparing geographical maps and aerial photographs. The available oldest map in Japan is 'Inouzu' chart, compiled in 1810 based on primitive but scientific survey techniques. In order to compensate for the distortion of the map, geometric correction was conducted for the Inouzu Chart for every $20 \mathrm{~km}$ section using several benchmarks identified along major streets, such as shrines and bridges. Maps surveyed in 1902, at the beginning of the Meiji Restoration, and those surveyed in 2000 to 2003 and photographs taken in 1947 and 1948 were also used for the analysis. Geometric distortion for the modern maps after the Meiji Restoration 1868 was confirmed to be negligibly small. Figure 8 shows the shoreline change of a town Tsuno located in the northern region, in which significant shoreline retreat as much as $100 \mathrm{~m}$ is identified. The shoreline change in the whole region is illustrated in Figure 9. Significant retreat is observed in the northern region whereas slight advancement is observed in the southern region. This suggests the direction of the longshore sand transport has been from north to south. Assuming the sediment volume lost in the northern part was transported to the south, we can calculate the mean rate of longshore sand transport in 200 years to be about 100 thousand cubic meter per year. The depth of closure in the beach profile was assumed to be $15 \mathrm{~m}$ in the calculation. On the average, however, the retreat is larger than the advancement, indicating the long-term deficit in the sediment budget in the whole area in spite of large sediment supply from the rivers. 

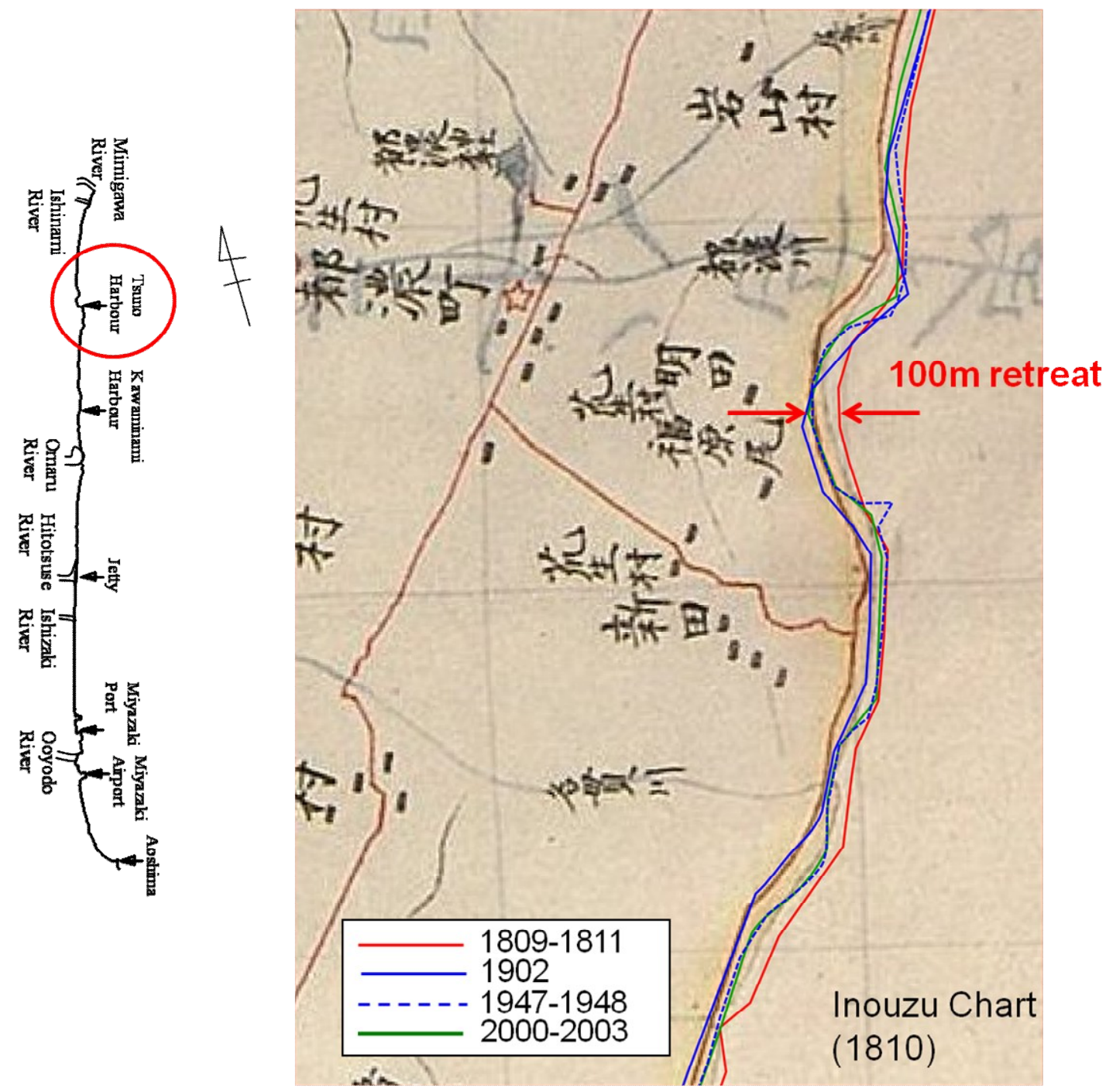

Figure 8 Shoreline retreat at Tsuno Town, northern part of the Miyazaki Coast, in 200 years illustrated on Inouzu Chart. 


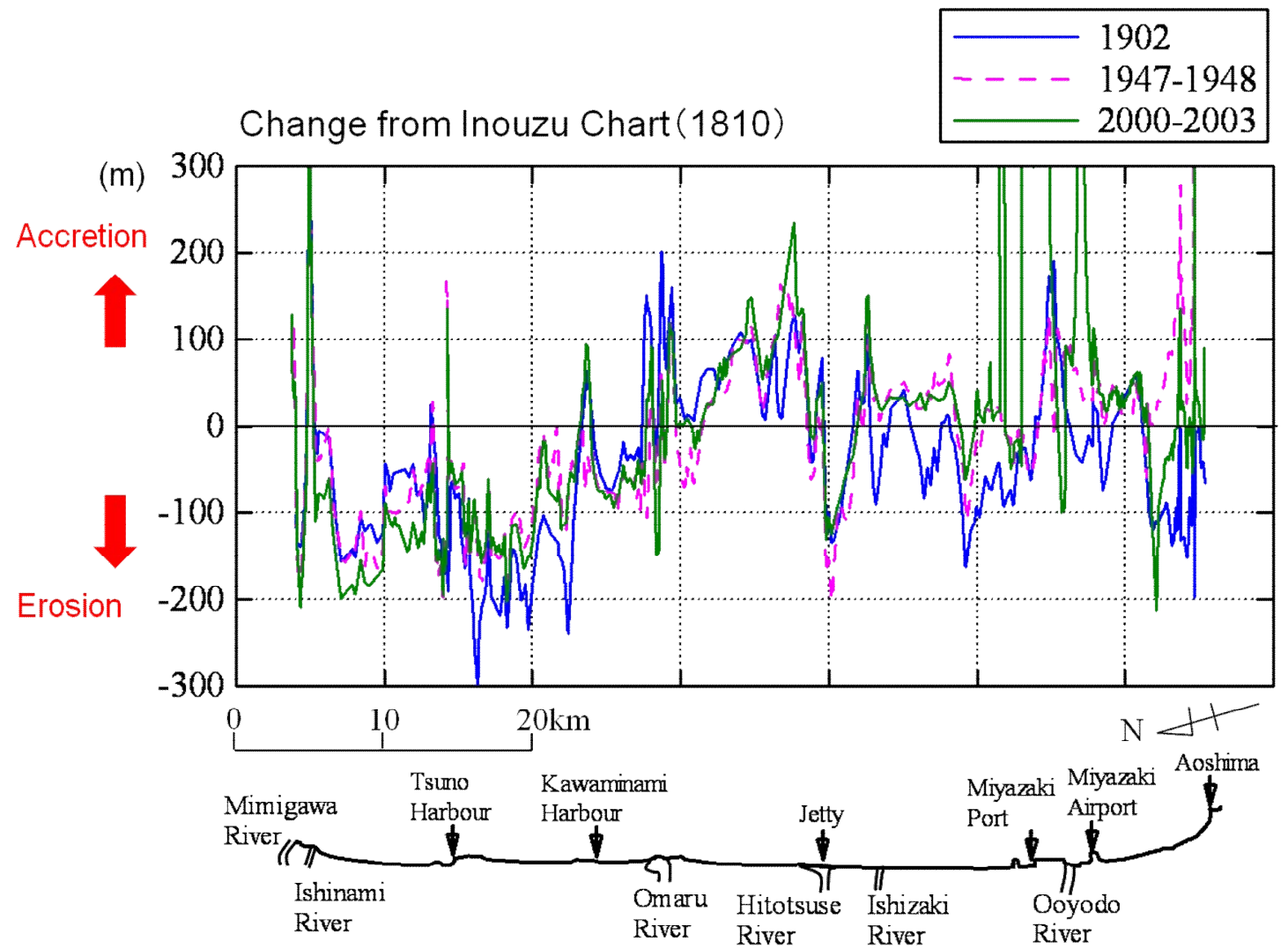

Figure 9 Shoreline change of the Miyazaki Coast in 200 years (reference to Inouzu Chart, 1810).

\section{BEACH SEDIMENT SIZE AND LUMINESCENCE}

Foreshore sediments at the high tide level were sampled on February 1, 2009, every $2 \mathrm{~km}$ in the region from the Mimigawa River to the Aoshima Island. Gravels were dominant on the northern coast between the Mimigawa River and the Omaru River, and sand was dominant on the southern coast. Figure 10 shows the size of gravel on the northern coast. The straight part of the scale in the photographs is $40 \mathrm{~cm}$. It is confirmed that the size of gravels is as large as 10 to $20 \mathrm{~cm}$ on the northern coast and gradually tends to become smaller on the southern coast. Sand grains $10 \mathrm{~cm}$ below the surface were taken by an opaque film container as shown in Figure 11. Sediments on the riverbed within $2 \mathrm{~km}$ from the river mouth were also sampled in the same manner. Sediment size was investigated for the fraction of sediment diameter $d$ smaller than 16mm. Figure 12 illustrates longshore distributions of median diameter. Blue data indicates the present study and the red ones are by Yoshitaka (1978). No significant change is observed in sediment diameter in 30 years. Since sediment size generally tends to decrease with longshore transport, overall direction of longshore sand transport is considered to be from north to south, although some peaks are noticed near river mouths. 
(1) Kokomi River mouth

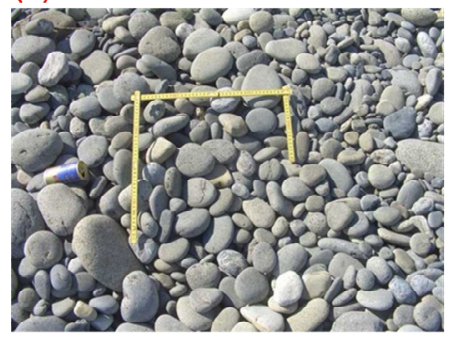

(4) Nanuki River south

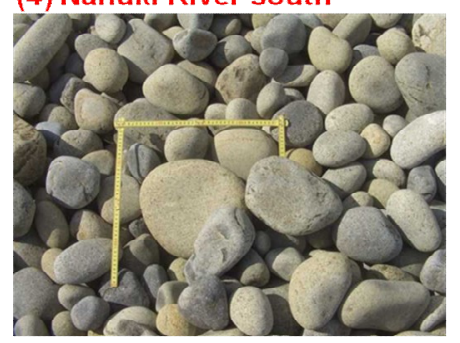

(2) Tsuno River mouth

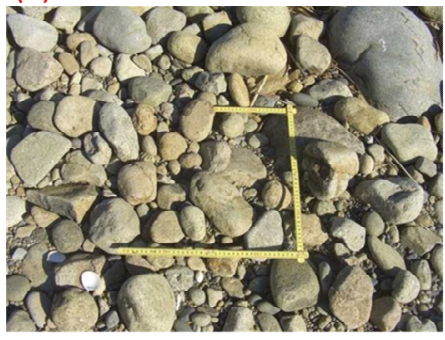

(5) Kawaminami Harbor
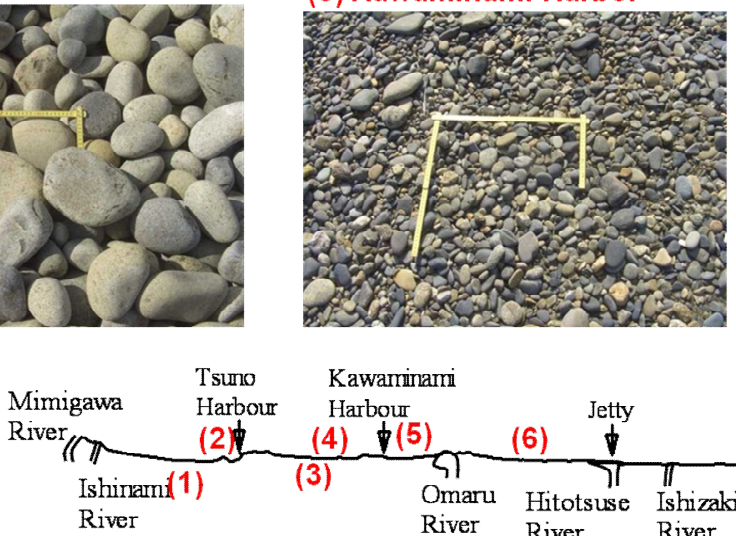

(3) Nanuki River mouth

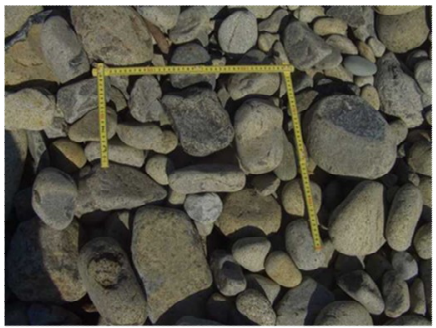

(6) Omaru River south

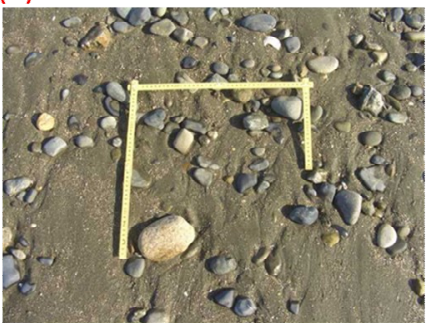

$$
\text { Miyazaki Miyazaki Aoshima }
$$

Figure 10 Gravel size on the northern coast (One straight part of the scale in the photo is $40 \mathrm{~cm}$ ).

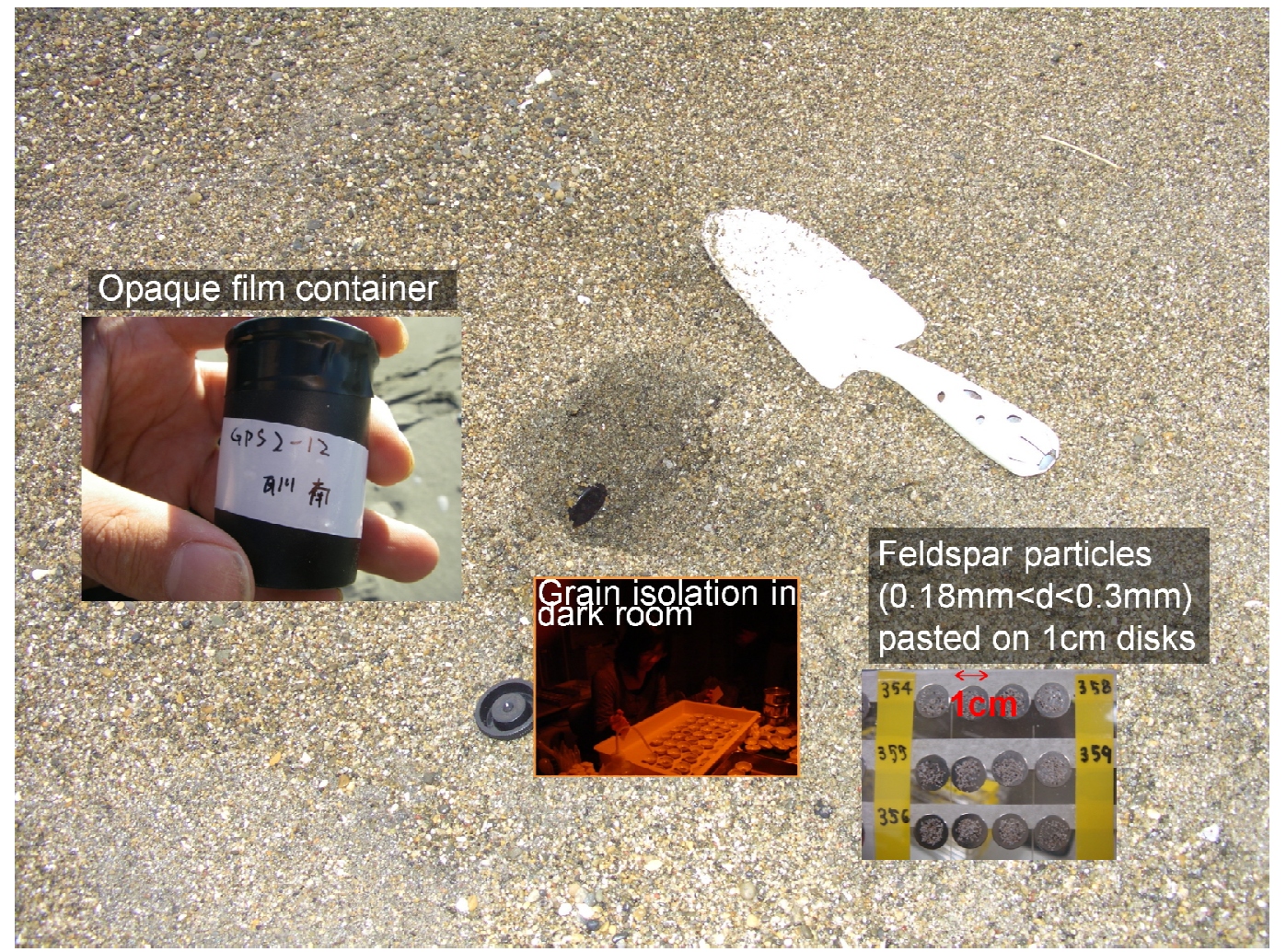

Figure 11 Sand sampling by an opaque film container and feldspar grain isolation for luminescence measurement. 


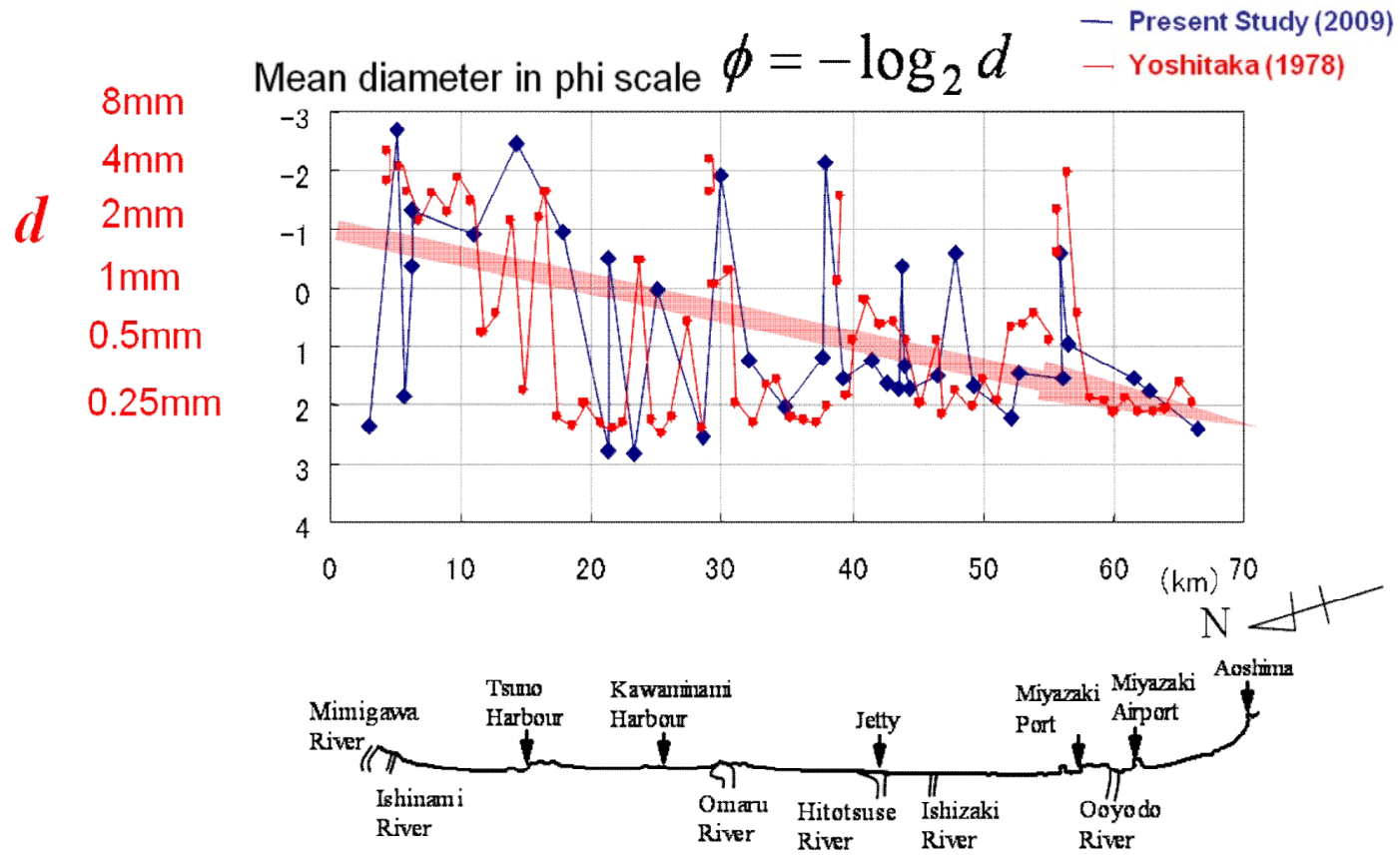

Figure 12 Longshore distribution of grain size for sand finer than $16 \mathrm{~mm}$.

The sediment samples were treated in a dark room to avoid exposure to extra light. After sieving $0.18-0.3 \mathrm{~mm}$ grain fraction and separation by heavy liquid, the potassium feldspar grains (K-feldspar; density less than $2.58 \mathrm{~g} / \mathrm{cm}^{3}$ ) were isolated (Liu et al., 2009). The isolated grains were pasted on a $1 \mathrm{~cm}$ diameter stainless disk to form a monolayer aliquot. The disk was then installed in the Risoe OSL/TL reader, which measured the Thermo-Luminescence (TL) intensity for natural and irradiated conditions. At least four disks were measured for one sample.

The luminescence intensity is an index of the duration of light exposure of quartz and feldspar particles. During the fluvial transport, sand particles decrease their luminescence intensity by the exposure to sunlight. The luminescence intensity can be measured by stimulating sand particles by thermal or optical energy. The luminescence intensity measured by thermal stimulation is called Thermo-Luminescence (TL) and that measured by light stimulation is called Optically Stimulated Luminescence (OSL). The sensitivity to light exposure is different in OSL and TL. Figure 13 indicates that the decay response of TL is of the order of several days, which is much longer that that of OSL (Liu et al., 2010). In this study, we utilized TL since we focus our attention to long-term movement of sediment particles.

Figure 14 illustrates the longshore distribution of TL intensities. TL intensities of riverine samples, illustrated by blue marks, are larger than those of coastal samples. This is because of short exposure time for sunlight in riverine transport processes. Oscillatory motion with strong mixing of sediments in surf zone and swash zone is considered to be effective in decreasing TL intensity. TL intensity is large in the northern beach, reflecting the short exposure to sunlight during the relatively short duration in the transport processes. TL intensity decreases to the south, indicating the direction of longshore transport is from the north to the south, which is found to be consistent with previous analyses based on geography, shoreline change and sediment size distribution. In the vicinity of the river mouth, however, TL intensity tended to decrease in the both directions, suggesting that the sediments discharged from the river are transported to the both sides around the river mouth. TL intensity becomes minimum at the Sumiyoshi Beach which is a severely eroding beach, where sand is considered to have been supplied from both sides. The decrease of sediment supply to the Sumiyoshi Beach is considered to be the reason of ongoing severe erosion. The sediment supply from the north has been decreased owing to the decrease in sediment supply from northern rivers, Mimigawa River, Omaru River and Hitotsuse River. The sediment supply from the south has been blocked by the breakwater of the Miyazaki Port, which was extended to the depth of $16 \mathrm{~m}$ in 1990. Furthermore, TL intensity is large at the location of nourishment, suggesting the possibility of tracing sediments by TL measurements. 


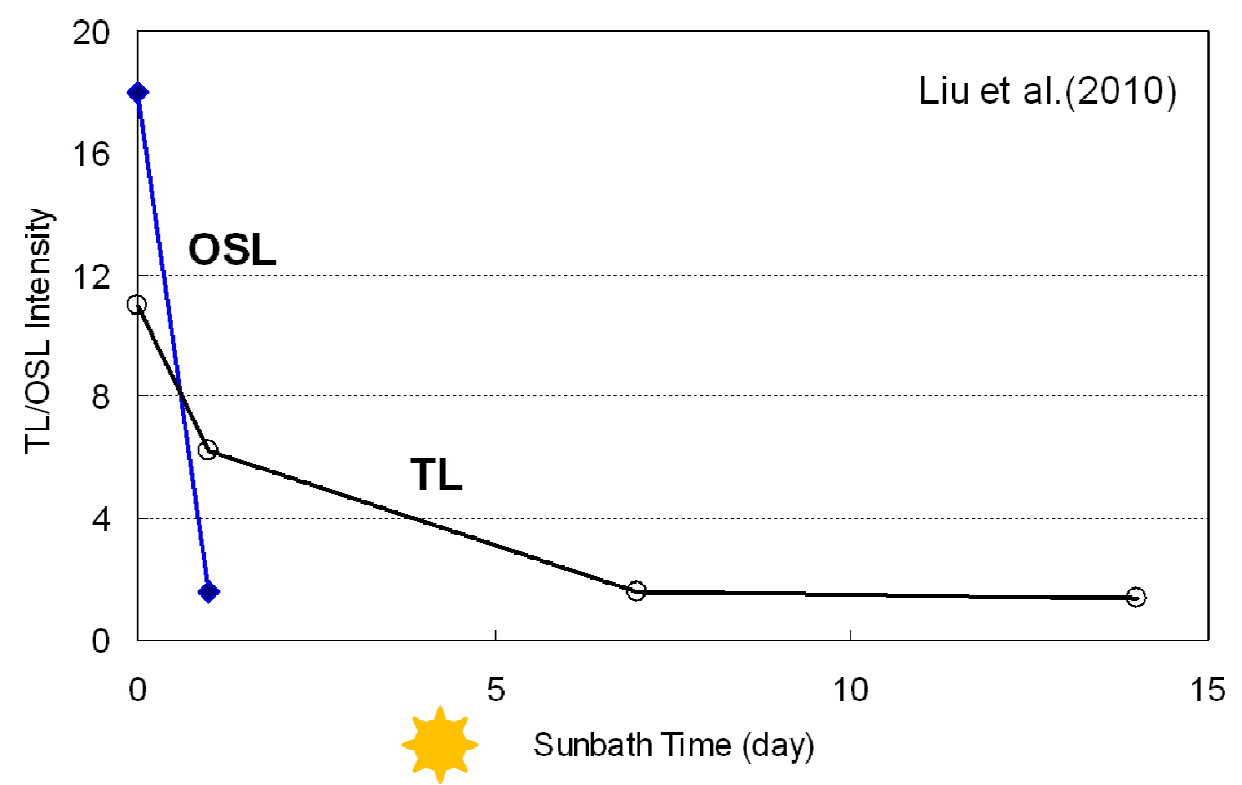

Figure 13 Decay time of luminescence intensities for feldspar grains (Liu et al., 2010).

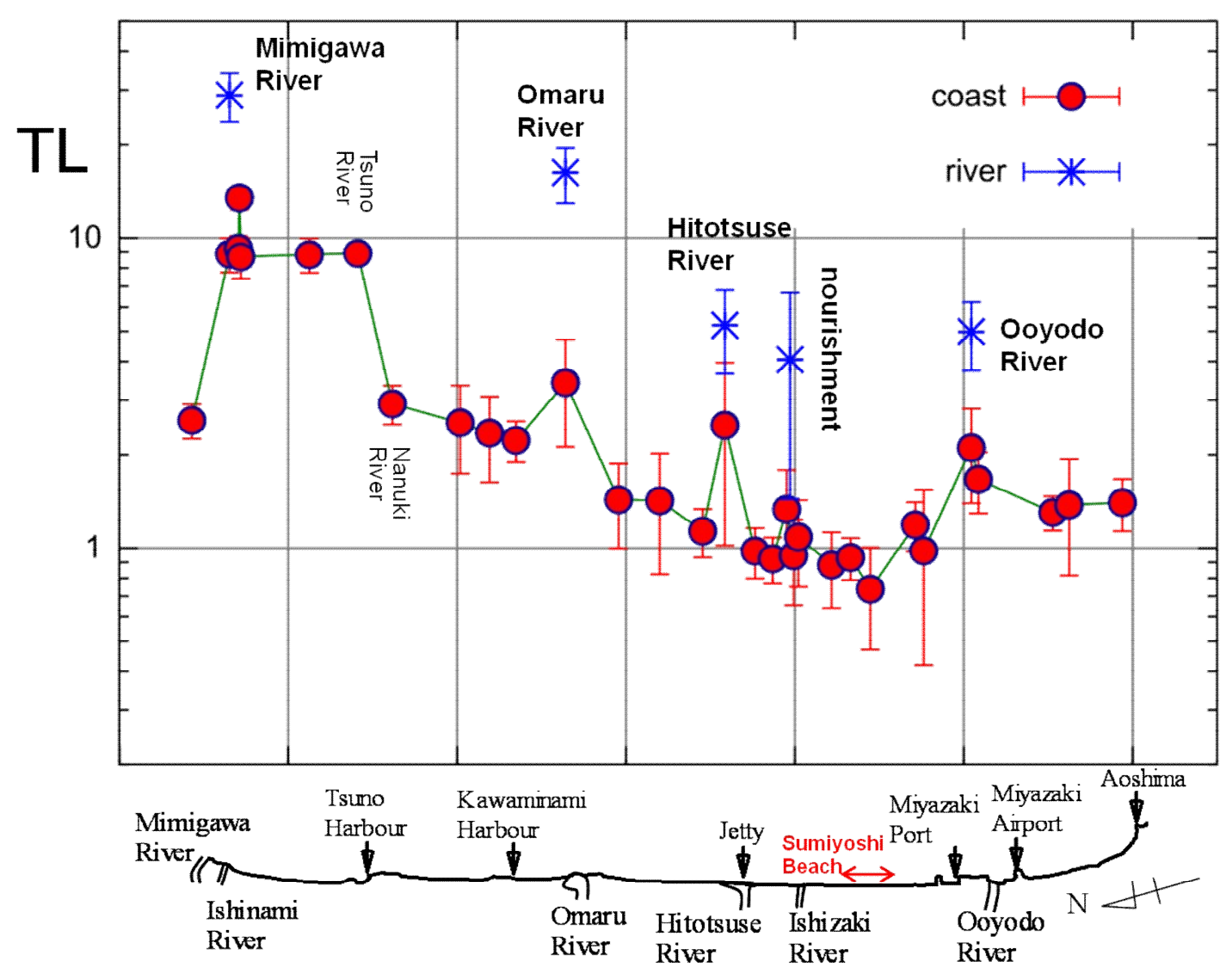

Figure 14 Longshore distribution of TL intensities. 


\section{CONCLUDING REMARKS}

Comparisons of a series of geographical maps for the Miyazaki Coast revealed the significant shoreline retreat in the northern region and slight advancement in the southern region. The sediment discharge from the rivers is considered to be decreased rapidly by sediment retention in reservoirs and rapid urbanization around the Miyazaki City. The longshore distribution of TL intensity and sediment size indicated that the direction of longshore transport is from north to south.

\section{ACKNOWLEDGMENTS}

The authors would like to express their sincere gratitude to Miyazaki Prefecture and Miyazaki Work Office of the Ministry of Land, Infrastructure, Transport and Tourism, for providing valuable data.

\section{REFERENCES}

Liu, H., S. Kishimoto, T. Takagawa, M. Shirai and S. Sato. 2009. Investigation of the sediment movement along the Tenryu-Enshunada fluvial system based on feldspar thermoluminescence properties, J. Coastal Research, 25, 5, 1096-1105.

Liu, H., A. Hamamoto and S. Sato. 2010. Investigation on the nourished sand movement in terms of luminescence measurements, J. Coastal Engineering, JSCE, 66, 1, 666-670 ( in Japanese ).

Yoshitaka, M., 1978, Sediment movement on the Hyuuganada Coast, Proc. $25^{\text {th }}$ conference on Coastal Engineering, JSCE, 274-278 ( in Japanese ).

Ashida, K. and T. Okumura, 1974, Study on sedimentation in reservoirs, Annual Report of Disaster Prevention Research Institute, Kyoto University, Vol. 17B, 555-570. 